\title{
Relational Social Justice Identity Development among Chinese International High School Students
}

\author{
Christine J. Yeh ${ }^{1}$, Suellen Lee ${ }^{2}$ \& Leyla Pérez-Gualdrón ${ }^{1}$ \\ ${ }^{1}$ School of Education, University of San Francisco, San Francisco, CA, USA \\ ${ }^{2}$ Westcoast Children's Clinic, Oakland, CA, USA \\ Correspondence: Christine J. Yeh, Department of Counseling Psychology, School of Education, University of \\ San Francisco, 2130 Fulton Street, San Francisco, 94117, CA, USA. Tel: 1-415-422-2347. E-mail: \\ cjyeh@usfca.edu
}

Received: August 22, 2016

doi:10.5539/jedp.v6n2p155
Accepted: September 6, $2016 \quad$ Online Published: September 26, 2016

URL: http://dx.doi.org/10.5539/jedp.v6n2p155

\begin{abstract}
This research explored the development of a social justice orientation and identity in a sample of high school students in Hong Kong. A sample of 12 students, four teachers, the Principal, and the School Counselor were interviewed in depth about the roles of community service, service learning, and social justice in their identities and school activities. Grounded theory was used to analyze the interview data and six main themes and several subcategories emerged: Six themes emerged from the interview data: (1) Community service as a social experience; (2) Service as a personally rewarding experience; (3) Appreciation of cultural differences; (4) Self-awareness and selflessness; (5) Adult support for social justice; and (6) Challenges in developing a social justice agenda. Implications for social justice identity development in counseling and education are discussed.
\end{abstract}

Keywords: social justice identity, international students, Chinese, relational identity

\section{Introduction}

In the past decade, the field of Counseling Psychology has further emphasized a social justice agenda (Blustein, Elman, \& Gerstein, 2002; Fouad, Gerstein, \& Toporek, 2006; Helms, 2003; Juntunen, Cavett, Clow, Rempel, Darrow, \& Guilmino, 2006; Toporek, Gerstein, Fouad, Roysircar, \& Israel, 2005) and specific researchers and counselors have begun to underscore the role that counseling psychologists can play in developing theory, research, practice, and training in social justice arenas as part of the larger mission associated with multicultural competence (e.g., Goodman, Liang, Helms, Latta, Sparks, \& Weintraub, 2004; Peréz-Gualdrón \& Yeh, 2014; Vera \& Speight, 2003). In order to encourage the development of social justice and community service oriented goals, it is critical that researchers understand the different aspects of a social justice identity and how it develops in youth. Hence, the current research investigates social justice identity development in a sample of high school students in Hong Kong. We were especially interested in an international sample because of the longstanding focus in the Asian community on service learning. A school, which included a community service-learning component was selected to help build theory on how social justice orientations develop in students. We were also interested in understanding the important role that school, teachers, students, and family members may have in fostering this process.

School-based service-oriented programs have been found to encourage positive effects on the political, social, civic, personal and academic development of adolescents (Furco \& Root, 2010; Yeh, Smith, \& Borrero, 2016). In fact, participation in service-learning experiences leads to important personal and social developmental outcomes (Billig \& Fruco, 2003), such as increased leadership capacity and social responsibility (Groh, Stallwood, \& Daniels, 2011), concern for others (Scales, Blyth, Berkas, \& Kielsmeier, 2000), acceptance of cultural diversity (Melchior \& Bailis, 2003), and greater comfort in communicating with diverse groups of people (Billig, 2000). Moreover, participation in community service has the potential to stimulate adolescents' political and moral identity development (Strain, 2005).

Although improved civic engagement and academic achievement are important goals for students participating in service-learning programs, from the perspective of the broader mission of social justice, creating meaningful changes in the communities that students serve is also an important outcome that is often less attended to in both 
practice and research (Yeh et al., 2014a). A critical aspect of the civic mission of schooling is fostering students' understanding and work toward a larger vision for equity and social justice (Wade, 2001). Although most educators and psychologists would agree that service-learning programs should be aligned with social justice goals, defining what social justice is and how students begin to develop a social justice identity is far more ambiguous.

There are multiple definitions for social justice identity in the literature and it is important for these multiple interpretations and perspectives to be available to students as they navigate what social justice means to them. Philosophical discussion of different paradigms may be found elsewhere (e.g., Vera \& Speight, 2003), but for the purposes of this paper we believe a social justice identity includes a "vision of a society in which the distribution of resources is equitable and all members are physically and psychologically safe and secure", and where there is "full and equal participation of all groups in a society" (Hooks, 1994, p. 3).

Empirical evidence suggests that service participation may be essential for the development of such a social justice identity. Building on Erikson's theory of identity development, Yates and Youniss (1996) theorized that youths' participation in service "stimulate reflection on society's political organization and moral order and one's agency in relation to these domains" and thereby "provide opportunities for identity development" (pp. 272-273). Service-learning as a pedagogical tool increases this potential by providing intellectual scaffolding and through structuring reflection (Brandenberger et al., 2013), to help shape youth's identity development. By analyzing adolescents' written reactions about their experiences working in a soup kitchen, Yates and Youniss provide preliminary support for these developmental processes.

Understanding the common characteristics and experiences of adults who demonstrated a commitment to social justice in their professional work may also inform how youth may develop a social justice orientation through community service experiences (Cipolle, 2010). Cipolle collected qualitative and quantitative data on adult alumni of a high-school service-learning program. The participants were selected because they identified as having lifestyle or career commitments to social justice related work. Common individual characteristics included family influences that instilled prosocial values and modeled service orientations, and educational influences such as the school mission, mentorship, teachers and institutional experiences that shaped their moral and civic identities. These influences encouraged reflection that clarified values and moral obligations. Common service experiences included participation in service projects at multiple sites over time from high school through college, service experiences overseas, and direct interactions with different ethnic and racial groups.

Cipolle (2010) concluded that besides individual characteristics that help motivate individuals to commit to social justice work, programmatic factors influenced the depth of educational impact and were also key in shaping the development of these individuals' social justice identity. Type of service experiences, especially ones that involved direct interactions with people in need (e.g., Schwarz, 2011), and the role of teachers as models and mentors were important. Cipolle surmises that service-learning experiences shaped these individuals' social justice identities by instilling an ethic of service, self-awareness, awareness of others, and an awareness of social issues. Moreover, the importance of family and educational role models in shaping social justice orientations is echoed by earlier research studies (Daloz, Keen, Keen, \& Parks, 1996; Stanton, Giles, \& Cruz, 1999) and in more recent research (Yeh et al., 2014a).

In social justice work, there have been three essential areas of development that have been emphasized: The affective dimension involves awareness of and sensitivity to issues of injustice and social inequity. The cognitive dimension involves an understanding of social systems and policies that cause and perpetuate conditions of social injustice. The volitional, or pragmatic, component involves a willingness to take action-what Freire (1970) refers to as "praxis" (Vera \& Speight, 2003).

Previous research provides us with a wealth of information on the development of adults who have already developed a well-defined social justice identity. However, we have yet to understand, how adolescents understand social justice conceptually, and how they begin to create meaning about social justice through their service experiences. Hence, the current research investigates the development of a social justice identity in a sample of high school students. This project focused on an international high school in Hong Kong as a case study in exploring the development of a social justice identity among high school students. An international school was specifically selected to highlight the importance of local as well as global citizenry and to understand how different cultures (in this case, Chinese culture) interprets a social justice mission. The selected school also had an international reputation and longstanding history of community service and social justice values so it had 
the potential to serve as a model program for understanding applications of social justice goals in educational settings.

\section{Method}

\subsection{Participant Characteristics}

The sample consisted of 17 participants from a high school in Hong Kong including students, teachers, and staff. There were two males and 10 females in the student sample $(\mathrm{M}=16$ years, range $=14-18$ years $)$. The students were in grades 9 to 12. Four of the students were Chinese, eight were biracial (Chinese/White European American). In addition, three White European American male teachers, a White European American female school counselor and a White European American male principal were also interviewed. Participants from various parts of the school community were interviewed in order to include multiple perspectives and experiences about our research question. The sample size reflects current norms for qualitative research (see Hill, Thompson, \& Williams, 1997, for elaboration). The multiple informants prioritize our interest in understanding multiple perspectives (Yeh, Kim, Pituc, \& Atkins, 2008) emphasizing youth interactions across different cultural contexts and with different school staff members.

\subsubsection{Research Design}

The data collection for the current study included interviews, observations, and document analysis. In-depth, semi-structured interviews with participants comprised the primary source of data for the study. The interviews lasted approximately 45-60 minutes and additional and probing questions were added when deemed important for enhancing the participant's voice (Mitra, 2009). All of the interviews were audiotaped, transcribed, and checked against the original recording for accuracy.

1) Community Site Visits. Each of the researchers visited the school on numerous occasions and sat in on classes, educational workshops, individual counseling sessions, after school programs, and staff meetings. These visits did not serve as the main data source for the study. Instead, they were intended to provide a validity check of the interview findings (Mitra, 2009) and a larger context for understanding how social justice is reinforced and situated in an ecological setting (Yeh, Borrero, Tito, \& Petaia, 2014b). Our visits included numerous interactions with the school staff, observations of students, and informal interactions. These visits as a form of data were purposive and offered insight into the school as a context for institutionally supporting social justice identity development.

Through the visits, it was clear that the school offered a range of service learning and community service activities, trips, and workshops. Hence, our observations provided information about an educational setting that supported social justice identity development among its students. The visits were primarily intended to provide a context for understanding in depth and in action, how systemically, an organization can build programs, curriculum, goals, that foster a social justice identity among its students. During our visits the first and second author met with staff members and discussed and wrote notes on our reflections of the space, surrounding community programs, and people.

2) Document and Media Analysis. In addition to the interviews and the school site visits, our data collection also included collecting pertinent documents such as website pages, internal printed materials and documents create by students and staff from the school. The documents created by high school students and staff were part of a service learning program at the school and they described various workshops, programs, trips, and initiatives that encouraged community service, learning, and involvement among students. The authors gathered the materials to help understand how social justice development is educationally supported at the school. This data was primarily used as a way to triangulate the interview findings.

\subsection{Establishing and Building Trustworthiness of Data}

Lincoln and Guba (1985) recommend different methods of establishing trustworthiness including triangulation, peer debriefing, and member checking. The purpose of peer debriefing is to explore part of the data that otherwise may be specific to the researcher's mind. The first author met with a peer regularly throughout the analysis stage to discuss the data. During the meetings, they shared and explored research plans, theoretical notes, and ideas for themes for critical feedback. In order to confirm the relevance, credibility, and validity of the data, we used member checking, which is the process of sharing and reviewing the findings, interpretations, and conclusions with at least one of the participants of the study (Yeh \& Inman, 2007). The data was shared with one of the participants in order to check and ensure that our analyses and interpretations were meaningful and 
credible to them. Their feedback was used to further refine the analyses and emergent themes (Lincoln \& Guba, 1985).

\subsection{Research Team}

Researchers are integrally bound to the research process as they shape and construct data, interpretations, analysis, and representations of meaning (Yeh \& Inman, 2007). In the present study, two of the authors served on the primary research team. They included one Taiwanese-American faculty member in Counseling Psychology, and one from Hong Kong, who received her Ph.D. in Clinical Psychology in the United States. The research team met and discussed possible biases, expectations, and assumptions about the data (Hill et al., 1997) and discussed potential power dynamics within the research group as well as between participant and researcher (Polkinghorne, 2005). The researchers also shared how we could approach this work with an open and natural attitude (Wertz, 2005). Prior to, and throughout the research process, we openly discussed how our positionality and experiences working with international schools may influence our perspectives (Suzuki, Ahluwalia, Mattis, \& Quizon, 2005).

\subsection{Biases and Expectations}

The authors' biases entering this research project included the belief that students in Hong Kong would appreciate and value the importance of doing community based work. We assumed they would be able to share meaningful experiences that relate to their service projects and they would understand what it means to have a social justice orientation. We also expected the students to have an understanding of how the school, the teachers, staff, and curriculum are geared to help them learn to be equity oriented community members. We believed that they would be able discuss various organizations that they are involved with locally. We think that the community experiences may influence how youth develop and think about themselves, but we think that perhaps their social justice identity would develop later (perhaps even after graduation when they have time to reflect on their experiences). We did not expect that the participants would spend a lot of time talking with their parents about their community experiences due to our bias that parents and children in Hong Kong do not always have open verbal communication about personal developmental issues. We did think the participants would share experiences with friends and in class but we were not sure they would deeply discuss the social justice implications of the work they are doing.

Each section of the interviews began with open-ended questions then specific follow-up questions were used as needed (Hill et al., 1997). A student version and a staff version of Social Justice Interview protocols were developed for the purposes of the project. The interview protocol was developed by the authors who have a longstanding personal and professional interest in social justice identity and community service. The interview questions were based on the research literature on service learning (Billig \& Fruco, 2003; Groh, Stallwood, \& Daniels, 2011; Scales, Blyth, Berkas, \& Kielsmeier, 2000) and social justice (Blustein, Elman, \& Gerstein, 2002; Goodman, Liang, Helms, Latta, Sparks, \& Weintraub, 2004). An expert in the field of service learning and social justice identity development provided guidance on the wording and terminology used to insure cultural relevance. Interview questions were developed and discussed by the research team. Questions were also shared with the Principal of the international school for feedback. Suggestions were incorporated into the final version of the interview protocol. The questions were then piloted with two high school students for additional feedback about wording and clarity of meaning.

\subsection{Social Justice Interview Protocol}

\subsubsection{Social Justice Interview Protocol (Student Version)}

The 19 interview questions were divided into the following areas: (a) background information (which included participants' age, gender, education level, grade point average, parent/guardian occupation, and years at the school); (b) descriptions of community service projects; (c) impact of doing community service; (d) support for doing community service; (e) benefits of doing community service; and (f) the relationship between community service and social justice. See Appendix A for student interview protocol.

\subsubsection{Social Justice Interview Protocol (Staff Version)}

The 13 interview questions were divided into the following areas: (a) background information (which included participants' age, gender, education level, previous work experience, race, and years at the school); (b) definitions of social justice; (c) strategies to foster social justice and interest in community service; (d) challenges in trying to foster social justice development; and (e) advice for other educators doing social justice work with students. See Appendix B for Staff Social Justice interview protocol. 


\subsection{Recruitment Procedure}

Student participants were recruited via informational posters that were displayed in common areas of the school. The two first authors conducted the interviews. Potential participants were informed that the research project was strictly voluntary and that they would receive monetary compensation for a voluntary 45- to 60-minute interview. The staff were selected based on the researchers' interest in interviewing staff in different positions at the school. All of the staff who were approached to participate, agreed to be interviewed. The participants were all interviewed in an office in the school. The interviews were then audio-taped and transcribed. Because the sample was non-random and selected in a deliberative manner to achieve a specific goal, it was considered purposive. However, the sample was also considered to be convenient because we selected potential participants who were at specific school site that we had access to. Parental, student, and individual consent forms were completed and signed as appropriate in accordance with university and school Institutional Review Board procedures.

\subsection{Data Analysis}

Interview data were analyzed utilizing grounded theory (Glaser \& Strauss, 1967). Interviews were transcribed, and two researchers first spent time reading and re-reading each of the transcripts before coding. Each researcher worked independently to identify units from the transcripts (Lincoln \& Guba, 1985), and then began taking notes in the margins of the documents to start categorizing the different units from a section of the data. This "open coding" was used to generate as many codes as possible. The two researchers then met to discuss their preliminary codes and began to investigate themes to which these codes spoke. Central themes were explored in depth (Strauss \& Corbin, 1990) and subcategories were discussed.

More "selective coding" followed, as each rater re-read transcripts and determined the core themes that had emerged from the data and listed them in a separate document. The researchers met to share themes with each other and determine the final themes. The discussion lasted until consensus was reached, and each researcher did one final read through to determine representative quotes for each theme. These identified quotes were among those selected for inclusion in the results section of the paper. The themes were shared with one of the participants for feedback and as a member check to insure they reflected the intent of the interviews. Then the third author reviewed all of the themes, corresponding quotes, and provided additional feedback for the discussion.

\section{Results}

Six themes emerged from the interview data: (1) Community service as a social experience; (2) Service as a personally rewarding experience; (3) Appreciation of cultural differences; (4) Self-awareness and selflessness; (5) Adult support for social justice; and (6) Challenges in developing a social justice agenda. Below we describe each of the main themes and offer some representative quotes for elaboration.

\subsection{Community Service as a Social Experience}

Most of the students in the sample described their community service as an important social experience. Specifically, community service experiences allowed the youth to make new friends, enjoy spending time with friends, and learn from their friends. The subcategories include: (a) Involvement based on a friend's recommendation, "because of the stories they told, they recruited more people to come and join the organization" and (b) Opportunity to bond with friends, "I didn't really know people I was with but we were all there for the same cause, so we bonded".

\subsection{Appreciation of Cultural Differences}

Community service experiences allowed youth to interact with and discover others who are different from them. Subcategories include (a) Language differences: "even though we didn't speak the same language it was just fun to know how we could still connect even though we're from two different worlds"; and (b) Socioeconomic differences: [about wanting to join Doctors without Borders] "it's getting to know more people who don't live in the same social status as you ... so I think it makes me more open to the world, and understand everyone's situations, but I won't judge them from far away."

\subsection{Service as a Personally Rewarding Experience}

Community service experiences were personally rewarding when youth felt positively about what they do and when they feel like they are actively collaborating with others. Subcategories include: (a) Deriving personal satisfaction, "at the end of the day, you feel good about it, you're like, wow, something's achieved". (b) Feeling appreciated by others, "it felt good to interact with them ... you could just tell how happy they were to see us ... 
it would just give us more incentive to work harder and finish the job of [building] the school"; (c) Being able to make an active contribution, "there is more than just donating money to certain charities ... [the school] has given me a bunch of opportunities to actually help people".

\subsection{Self-Awareness \& Selflessness}

Service activities allowed youth the opportunity to reflect on their lives, particularly on their privilege, and the needs of others who are less privileged. Subcategories include: (a) Personal growth, "I definitely think you grow as a person, for sure you become more mature because for the first time, it's not just about you even though you're having fun", (b) Developing desire to help others in the future: service experiences helped youth develop a desire to contribute to social causes and help others in the future, "I want to do something that somehow impacts our community", and (c) Learning to think about others first: service experiences encouraged youth learn to think about the needs of others beyond their own needs, "you just learn more about thinking about other people, more than just yourself".

\subsection{Adult Support for Social Justice}

Adults can play an instrumental role in guiding, encouraging commitment, and inspiring passion in youth's service involvement. Subcategories include: (a) Inspiring teachers, "he gets really passionate about it! ... I think that way it gets into our heads better. I like the way he gets very passionate about it, so he keeps repeating it. So it's good", (b) Family support: parents played an instrumental role in supporting and talking to youth about their involvement in service-oriented activities, "after every shift I'd call my mother and tell her how it went... And she's always been really supportive of it, I think she just worried it would take up too much of my time and I should be devoting more of my time to my studies".

\subsection{Challenges in Developing a Social Justice Agenda}

Providing service opportunities that help youth learn to commit to serving others and pursue social justice posed important challenges. Subcategories include: (a) Competing demands on time, "it sometimes collides with my coursework, or my homework, but I'm learning to handle it". (b) Need encouragement to do service, "I think, maybe a little bit more pressure would be better ... I think sometimes kids our age are not, you know, we don't look forward to going and taking hours off our leisure time to go do work, but I think ... they just need to give us a really big push to tell us, you have to do it". (c) Lack of commitment from some teachers is discouraging, "some teachers don't feel like they should really be there ... I think they should be genuinely interested in doing it, so it's truly enforced in the student".

\section{Discussion}

This research project investigated how high school students begin to develop a social justice identity through community engagement, service learning, social justice, and compassion through an integrated community service project at a school in Hong Kong. Relatively little is known about the development of a social justice identity among high school students in the literature in counseling psychology and yet adolescents are increasingly asked to consider the role of community service in their lives. Moreover, the growing multicultural and social justice agendas in counseling psychology support additional scrutiny in these areas of research.

Our findings reflect some of the current understandings of social justice principles yet simultaneously offer new perspectives to consider. For example, the theme, Self-awareness and selflessness is very similar to the core principle, Ongoing self-examination as described by Goodman et al. (2004) as both focus on the importance of understanding one's worldview, perspective, and privilege in doing social justice work. This theme also focuses on how youths' self-awareness also led to an increased interest in becoming selfless. Students in our sample linked their own self-awareness of privilege with needing to, and having a desire to, support others.

\subsection{Towards a Relational Theory of Social Justice Identity Development}

The social justice principles stated by Goodman et al. (2004) tend to focus on issues of empowerment and voice within the individual. In contrast to this focus on self, the sample from Hong Kong centered on the role of relationships in the development of their social justice identity. Specifically, the themes of Community service as a social experience, Discovery of different others, and Adult support for social justice, among others, concentrated on how friends, parents, and educators encouraged and fostered identities around supporting others. This emphasis on personal and academic relationships and the role of relationships in their conceptualizations of community service and social justice highlights the interdependent and social emphasis in Asian cultures (Wang, Wei, \& Chen, 2015; Yeh, 2002; Yeh \& Hwang, 2002). These interpersonal themes also expand current 
definitions of social justice beyond personal empowerment and voice to include the role of relationships in developing a social justice identity.

The current findings also reflect previous research documenting the interrelationship between engaging in community service and social justice. Researchers have described the personal and societal benefits of having more civically connected and empowered youths in the face of inequity (e.g., Cammarota, 2004; Diemer, 2009; Ginwright \& Cammarota, 2007; Solórzano-Bernal, 2001; Watts et al., 2003; Watts et al., 1999; Watts \& Flanagan, 2007). This research contributes to the limited work on how social justice may be connected to community engagement and action. More specific empirical evidence is needed to more fully understand how community engagement and learning contribute to social justice orientation (Yeh \& Borrero, 2012). Authors contend that the benefits of community engagement are key in the successful transition from adolescence to emerging adulthood in adolescents of Color (e.g., Cammarota, 2004; Ginwright \& Cammarota, 2007; Watts et al., 2003; Yeh et al., 2014a). We would extend this assertion to include international students who are navigating living in another country and making sense of their role as service learners in a new community.

Our findings also build on Watts et al.'s (2003) sociopolitical development theory. Watt's contends that sociopolitical development is the capacity to acknowledge unfairness and oppression (i.e., critical consciousness) and being motivated to change them for promoting social justice (i.e., social justice orientation). Our results extend this model by also focusing on the important role of relationships in building a social justice identity. Moreover, we also found that youth also need to navigate multiple challenges as they navigate doing community service and equity oriented work.

The results from our interviews also connect well with research on sociopolitical socialization (Diemer, Hsieh, \& Pan, 2009). Diemer et al. (2009) found that parental and social influences are important when understanding youths' sociopolitical development. Further, Diemer (2012) explored the longitudinal roles of parental political socialization and youth sociopolitical development and how sociopolitical development may be encouraged by parental encouragement and action. We also found that parents and adults may play an important role in how youth develop a social justice identity. Although we did not study sociopolitical development in particular, we believe it is strongly related to social justice identity.

\subsection{Limitations}

There are a few limitations related to this research study that should be noted. First, the sample included high school students from a specific international school in Hong Kong. Hence, we caution generalizing our results to other students who may vary in terms of geographic location, school context, and grade level. Future investigations should examine how social justice identity develops in other school and community contexts.

There are also limitations associated with the design of the study. First, we used interviews, site visits, and document analysis as our primary means of data collection. Hence, our research is limited by our focus on using qualitative data and a small sample size. Future research studies may begin to focus on quantitatively measuring the development of social justice identity and the variables associated with this important developmental period. The cross-sectional nature of our data and our reliance on the use of participant self-report also limits accuracy. Participants in our sample may have responded to survey questions in a socially desirable way (Tracey, 2016).

\subsection{Implications}

Our research qualitatively investigated how a sample of students at an international school in Hong Kong begins to develop a social justice identity in the context of their service learning experiences. Increasingly, schools are integrating service learning requirements, initiatives, and options to address a growing need in society and to perhaps align with college admissions criteria. This research informs theory about social justice in counseling psychology by extending current conceptualizations to include more attention to the role and critical nature of relationships in social justice identity development. Our work also has implications for high schools wishing to foster a social justice identity among their students. Specifically, our findings call attention to the important role that families and teachers play in supporting and motivating youth to focus on justice oriented work. We encourage educational settings to continue to find ways to support their students' interest in social justice identity development.

In terms of specific counseling psychology practice implications, we believe this research can inform school counseling practice in high schools and in international schools. It is clear that adult relationships have the potential to foster social justice identities among students. Since school counselors are often providing career and personal counseling to students, they are in a unique position to support and encourage students in their social 
justice work and interests. Based on our specific findings, school counselors may serve an important role in helping students with their own self-examination, addressing challenges in social justice work, and in building relationships in their service learning projects.

\section{References}

Billig, S. H. (2000). Research on K-12 school-based service learning: The evidence builds. Phi Delta Kappan, $81(9), 658$.

Billig, S., \& Furco, A. (2003). Research agenda for K-12 service-learning: A proposal to the field. In A. Furco, \& S. H. Billig (Eds.), Service-Learning: The Essence of the Pedagogy (pp. 271-280). Greenwich, CO: Information Age Publishing, Inc.

Blustein, D., Elman, N., \& Gerstein, L. (2002). Executive report on social action groups. National Counseling Psychology Conference, Houston.

Brandenberger, J. W., Deardorff, D. K., Edward, K. E., Chism, N. V. N., Palmer, M. M., Price, M. F., \& Katz, J. (2013). 2.4 Investigating personal development outcomes in service learning. In Research on Service Learning: Conceptual Frameworks and Assessment: Communities, Institutions, and Partnership (Vol. 2, p. 234).

Cammarota, J. (2004). The gendered and racialized pathways of Latina and Latino youth: Different struggles, different resistances in the urban context. Anthropology \& Education Quarterly, 35, 53-74. http://dx.doi.org/10.1525/aeq.2004.35.1.53

Cipolle, S. B. (2010). Service-learning and social justice: Engaging students in social change. Lanham, MA: Rowman \& Littlefield, Inc.

Daloz, L., Keen, C., Keen, J., \& Parks, S. (1996). Common fire: Leading lives of commitment in a complex world. Boston MA: Beacon Press.

Diemer, M. A. (2009). Pathways to occupational attainment among poor youth of color: The role of sociopolitical development. The Counseling Psychologist, 37, 6-35. $\mathrm{http}: / / \mathrm{dx}$.doi.org/10.1177/0011000007309858

Diemer, M. A. (2012). Fostering marginalized youths' political participation: Longitudinal roles of parental political socialization and youth sociopolitical development. American Journal of Community Psychology, 50, 246-256. http://dx.doi.org/10.1007/s10464-012-9495-9

Diemer, M. A., Hsieh, C., \& Pan, T. (2009). School and parental influences on sociopolitical development among poor adolescents of color. The Counseling Psychologist, 37, 317-344. http://dx.doi.org/10.1177/0011000008315971

Du, Y., \& Wei, M. (2015). Acculturation, enculturation, social Connectedness, and subjective well-being among Chinese international students. The Counseling Psychologist, 43(2), 299-325. http://dx.doi.org/10.1177/0011000014565712

Fouad, N. A., Gerstein, L. H., \& Toporek, R. L. (2006). Social justice and counseling psychology in context. In Handbook for social justice in counseling psychology: Leadership, vision, and action (pp. 1-16). http://dx.doi.org/10.4135/9781412976220.n1

Freire, P. (1970). Pedagogy of the oppressed. New York: Continuum International.

Furco, A., \& Root, S. (2010). Research demonstrates the value of service learning. Phi Delta Kappan, 91(5), 16-20. http://dx.doi.org/10.1177/003172171009100504

Ginwright, S., \& Cammarota, J. (2002). New terrain in youth development: The promise of a social justice approach. Social Justice, 29(90), 82-95.

Glaser, B., \& Strauss, A. (1967). The discovery of grounded theory. Chicago: Aldine.

Goodman, L. A., Liang, B., Helms, J. E., Latta, R. E., Sparks, E., \& Weintraub, S. R. (2004). Training counseling psychologists as social justice agents feminist and multicultural principles in action. The Counseling Psychologist, 32(6), 793-836. http://dx.doi.org/10.1177/0011000004268802

Groh, C. J., Stallwood, L. G., \& Daniels, J. J. (2011). Service-learning in nursing education: Its impact on leadership and social justice. Nursing Education Perspectives, 32(6), 400-405. http://dx.doi.org/10.5480/1536-5026-32.6.400 
Helms, J. E. (2003). A pragmatic view of social justice. The Counseling Psychologist, 31(3), 305-313. http://dx.doi.org/10.1177/0011000003031003006

Hill, C. E., Thompson, B. J., \& Williams, E. N. (1997). A guide to conducting consensual qualitative research. The counseling psychologist, 25(4), 517-572. http://dx.doi.org/10.1177/0011000097254001

Hooks, B. (1994). Teaching to transgress: Education as the practice of freedom. New York: Routledge.

Ivey, A. E., \& Collins, N. M. (2003). Social justice: A long-term challenge for counseling psychology. The Counseling Psychologist, 31(3), 290-298. http://dx.doi.org/10.1177/0011000003031003004

Juntunen, C. L., Cavett, A. M., Clow, R. B., Rempel, V., Darrow, R. E., \& Guilmino, A. (2006). Social justice through self-sufficiency Vocational psychology and the transition from welfare to work. In Handbook for social justice in counseling psychology: Leadership, vision, and action (p. 294).

Lincoln, Y. S., \& Guba, E. G. (1985). Naturalistic inquiry. Beverly Hills, CA: Sage.

Loesch-Griffin, D., Petrides, L. A., \& Pratt, C. (1995). A comprehensive study of project yes-rethinking classrooms and community: Service-learning as educational reform. San Francisco: East Bay Conservation Corps.

Melchior, A., \& Bailis, L. N. (2003). Impact of service-learning on civic attitudes and behaviors of middle and high school youth: Findings from three national evaluations. In A. Furco, \& S. H. Billig (Eds.), Service-Learning: The Essence of the Pedagogy (pp. 201-222). Greenwich, CO: Information Age Publishing, Inc.

Mitra, D. L. (2009). Collaborating with students: Building youth-adult partnerships in schools. American Journal of Education, 115, 407-436. http://dx.doi.org/10.1086/597488

Peréz-Gualdrón, L., \& Yeh, C. J. (2014). Counseling for Social Justice and Multicultural Individuals. In V. Benet-Martínez, \& Y. Y. Hong (Eds.), The Oxford Handbook of Multicultural Identity: Basic and Applied Psychological Perspectives. Oxford University Press: New York. http://dx.doi.org/10.1093/oxfordhb/9780199796694.013.020

Polkinghorne, D. E. (2005). Language and meaning: Data collection in qualitative research. Journal of Counseling Psychology, 52(2), 137. http://dx.doi.org/10.1037/0022-0167.52.2.137

Scales, P. C., Blyth, D. A., Berkas, T. H., \& Kielsmeier, J. C. (2000). The effects of service-learning on middle school students' social responsibility and academic success. Journal of Early Adolescence, 20, 332-358. http://dx.doi.org/10.1177/0272431600020003004

Schwarz, K. C. (2011). Students' interactions with service recipeints while completing Ontario's community involvement requirement. In B. Porfilio, \& H. Hickman (Eds.), Critical Service Learning as a Revolutionary Pedagogy: A Project of Student Agency in Action (pp. 29-46). Charlotte, NC: Information Age Publishing.

Solórzano, D. G., \& Bernal, D. D. (2001). Examining transformational resistance through a critical race and LatCrit theory framework: Chicana and Chicano Students in an urban context. Urban Education, 36, 308-342. http://dx.doi.org/10.1177/0042085901363002

Stanton, T., Giles, D., \& Cruz, N. (1999). Service-learning: A movement's pioneers reflect on its origins, practice and future. San Francisco, CA: Jossey-Bass Inc.

Strain, C. R. (2005). Pedagogy and practice: Service-learning and students' moral development. New Directions for Teaching and Learning, 2005(103), 61-72. http://dx.doi.org/10.1002/tl.204

Strauss, A., \& Corbin, J. (1990). Basics of qualitative research: Grounded theory procedures and techniques. Newbury Park, CA: Sage.

Suzuki, L. A., Ahluwalia, M. K., Mattis, J. S., \& Quizon, C. A. (2005). Ethnography in counseling psychology research: Possibilities for application. Journal of Counseling Psychology, 52(2), 206. http://dx.doi.org/10.1037/0022-0167.52.2.206

Toporek, R. L., Gerstein, L., Fouad, N., Roysircar, G., \& Israel, T. (2005). Handbook for social justice in counseling psychology: Leadership, vision, and action. Sage Publications: NY.

Tracey, T. J. G. (2016). A note on socially desirable responding. Journal of Counseling Psychology, 63, 224-232. http://dx.doi.org/10.1037/cou0000135 
Vera, E. M., \& Speight, S. L. (2003). Multicultural competence, social justice, and counseling psychology: Expanding our roles. The Counseling Psychologist, 31(3), 253-272. http://dx.doi.org/10.1177/0011000003031003001

Wade, R. (2001). “...And justice for all” Community service-learning for social justice (Education Commission of the States Issue Paper). Retrieved November 26, 2014, from http://www.ecs.org/clearinghouse/29/13/2913.htm

Wang, K. T., Wei, M., \& Chen, H. H. (2015). Social factors in cross-national adjustment subjective well-being trajectories among Chinese international students. The Counseling Psychologist, 43(2), 272-298. http://dx.doi.org/10.1177/0011000014566470

Watts, R. J., \& Flanagan, C. (2007). Pushing the envelope on youth civic engagement: A developmental and liberation psychology perspective. Journal of Community Psychology, 35, 779-792. http://dx.doi.org/10.1002/jcop.20178

Watts, R. J., Griffith, D. M., \& Abdul-Adil, J. (1999). Sociopolitical development as an antidote for oppression: Theory and action. American Journal of Community Psychology, 27, 225-271. http://dx.doi.org/10.1023/a:1022839818873

Watts, R. J., Williams, N. C., \& Jagers, R. J. (2003). Sociopolitical development. American Journal of Community Psychology, 31, 185-194. http://dx.doi.org/10.1023/A:1023091024140

Wertz, F. J. (2005). Phenomenological research methods for counseling psychology. Journal of counseling psychology, 52(2), 167. http://dx.doi.org/10.1037/0022-0167.52.2.167

Yates, M., \& Youniss, J. (1996). A developmental perspective on community service in adolescence. Social Development, 5(1), 85-111. http://dx.doi.org/10.1111/j.1467-9507.1996.tb00073.x

Yeh, C. J. (2002). Taiwanese students' gender, age, interdependent and independent self-construal, and collective self-esteem as predictors of professional psychological help-seeking attitudes. Cultural Diversity and Ethnic Minority Psychology, 8(1), 19-29. http://dx.doi.org/10.1037/1099-9809.8.1.19

Yeh, C. J., \& Borrero, N. E. (2012). Evaluation of a health careers program for Asian American and Pacific Islander high school students. Journal of Multicultural Counseling and Development, 40, 227-239. http://dx.doi.org/10.1002/j.2161-1912.2012.00020.x

Yeh, C. J., Borrero, N. B., Lusheck, C., Placencia, L., Kilano, S., Mase, M., ... Tito, P. (2014a). Fostering social support, leadership competence, community engagement and resilience among Samoan American youth. Asian American Journal of Psychology, 6, 145-153. http://dx.doi.org/10.1037/a0038545

Yeh, C. J., Borrero, N. E., Tito, P., \& Petaia, L. S. (2014b). Intergenerational stories of "othered" youth through insider cultural knowledge and community assets. The Urban Review, 46, 147-168. http://dx.doi.org/10.1007/s11256-013-0249-2

Yeh, C. J., \& Hwang, M. (2000). Interdependence in ethnic identity and self: Implications for theory and practice. $\begin{array}{lllll}\text { Journal of Counseling and } & \text { 420-429. }\end{array}$ http://dx.doi.org/10.1002/j.1556-6676.2000.tb01925.x

Yeh, C. J., \& Inman, A. G. (2007). Qualitative data analysis and interpretation in counseling psychology: Strategies for best practices. The Counseling Psychologist, 35, 369-403. http://dx.doi.org/10.1177/0011000006292596

Yeh, C. J., Kim, A. B., Pituc, S. T., \& Atkins, M. (2008). Poverty, loss, and resilience: The story of Asian

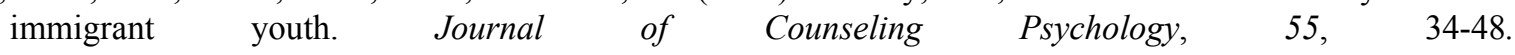
http://dx.doi.org/10.1037/0022-0167.55.1.34

Yeh, C. J., Smith, D., \& Borrero, N. E. (2016). Anticolonial and indigenous perspectives and strategies for counseling interventions. In J. G. Ponterrotto, J. M. Casas, L. A. Suzuki, \& C. M. Alexander (Eds)., Handbook of multicultural counseling (4th ed., pp. 188-196). Thousand Oaks, CA: Sage Publications Inc.

Zaff, J., \& Lerner, R. (2010). Service learning promotes positive youth development in high school. Phi Delta Kappan, 91(5), 21-23. http://dx.doi.org/10.1177/003172171009100505 


\section{Appendix A}

\section{Student Social Justice Interview Protocol}

1) Gender:

2) How old are you?

3) What grade are you in?

4) What is your GPA?

5) What do your parents'/guardians' occupation?

6) What is your ethnic/racial background?

7) How long have you been at this school?

8) What types of community service projects have you been involved in? At CIS? Outside CIS? can you give an example of a student project you did related to your community service project?

9) How do you feel about doing community service?

10) Tell me about the ways doing community service has affected your development (social, moral, emotional, spiritual, political development). Please give examples?

11) In what ways has CIS and your community service project affected your identity? Describe your most meaningful/least meaningful service experience. Why were they meaningful/not meaningful?

12) How do your teachers and courses help you in your community service experiences? Describe a class experience where your teacher helped make some connection with your service experience.

13) Do you and your friends talk about your service experiences?

14) Do you share your experiences with your parents? What do you talk to them about?

15) What are some strengths and weaknesses of school's curriculum as it relates to community learning?

16) What are some of the main benefits of the community service program? Please describe how this is beneficial? What are some weaknesses?

17) What does social justice mean to you? How would you define this? How does CIS foster a social justice orientation among students, teachers and staff?

18) How does CIS foster a social justice orientation among its students? (this includes building compassion, facilitating awareness of oppressive conditions, building consciousness in oppressed communities, etc.).

19) Do you think you will continue to be involved in the community after you graduate from CIS? Why or why not?

\section{Appendix B}

\section{Staff Social Justice Interview Protocol}

1) Gender:

2) How old are you?

3) What is your educational background?

4) What is your previous work experience?

5) What is your ethnic/racial background?

6) How long have you been teaching at this school?

7) Why did you decide to work here?

8) What does social justice mean to you?

9) What are some techniques you use to teach students about social justice? Examples ...

10) What are some techniques you use to teach students about service to the community? Examples ...

11) What are some of the challenges in this work? Examples ...

12) How do you motivate students to be involved in social justice work?

13) What advice do you have for other teachers/staff interested in this work?

\section{Copyrights}

Copyright for this article is retained by the author(s), with first publication rights granted to the journal.

This is an open-access article distributed under the terms and conditions of the Creative Commons Attribution license (http://creativecommons.org/licenses/by/4.0/). 